BNL-7 9428-2007-CP

\title{
Design and performance of the matching beamline between the BNL EBIS and an RFQ
}

\author{
J. Alessi, E. Beebe, J. Brodowski, A. Kponou, M. Okamura, \\ A. Pikin, D. Raparia, J. Ritter, L. Snydstrup, V.Zajic
}

Presented at the 21st Particle Accelerator Conference

Albuquerque, New Mexico

June $25-29,2007$

\author{
Collider-Accelerator Department \\ Brookhaven National Laboratory \\ P.O. Box 5000 \\ Upton, NY 11973-5000 \\ www.bnl.gov
}

Notice: This manuscript has been authored by employees of Brookhaven Science Associates, LLC under Contract No. DE-AC02-98CH10886 with the U.S. Department of Energy. The publisher by accepting the manuscript for publication acknowledges that the United States Government retains a non-exclusive, paid-up, irrevocable, world-wide license to publish or reproduce the published form of this manuscript, or allow others to do so, for United States Government purposes. 


\section{DISCLAIMER}

This report was prepared as an account of work sponsored by an agency of the United States Government. Neither the United States Government nor any agency thereof, nor any of their employees, nor any of their contractors, subcontractors, or their employees, makes any warranty, express or implied, or assumes any legal liability or responsibility for the accuracy, completeness, or any third party's use or the results of such use of any information, apparatus, product, or process disclosed, or represents that its use would not infringe privately owned rights. Reference herein to any specific commercial product, process, or service by trade name, trademark, manufacturer, or otherwise, does not necessarily constitute or imply its endorsement, recommendation, or favoring by the United States Government or any agency thereof or its contractors or subcontractors. The views and opinions of authors expressed herein do not necessarily state or reflect those of the United States Government or any agency thereof. 


\title{
DESIGN AND PERFORMANCE OF THE MATCHING BEAMLINE BETWEEN THE BNL EBIS AND AN RFQ*
}

\author{
J. Alessi" ${ }^{\#}$ E.Beebe, J.Brodowski, A.Kponou, M.Okamura, A.Pikin, D.Raparia, J.Ritter, \\ L.Snydstrup, V.Zajic, \\ BNL, Upton, NY 11973 U.S.A.
}

\section{Abstract}

A part of a new EBIS-based heavy ion preinjector, the low energy beam transport (LEBT) section between the high current EBIS and the RFQ is a challenging design, because it must serve many functions. In addition to the requirement to provide an efficient matching between the EBIS and the RFQ, this line must serve as a fast "switchyard", allowing singly charged ions from external sources to be transported into the EBIS trap region, and extracted, highly charged ions to be deflected to off-axis diagnostics (time-of-flight or emittance). The space charge of the $5-10 \mathrm{~mA}$ extracted heavy ion beam is a major consideration in the design, and the space charge force varies for different ion beams having $Q / m$ from 10.16 . The line includes electrostatic lenses, spherical and parallel-plate deflectors, magnetic solenoid, and diagnostics for measuring current, charge state distributions, emittance, and profile. A prototype of this beamline has been built, and results of tests are presented.

\section{INTRODUCTION}

A new EBIS-based heavy ion preinjector is under construction at Brookhaven National Laboratory [1]. This preinjector will provide enhanced capabilities for both RHIC and the NASA Space Radiation Laboratory (NSRL). To meet the needs of both programs, the preinjector must fulfill the performance requirements given in Table I. Pulse width is chosen to allow 1-4 turn injection into Booster. Peak currents of the single ion charge state are $\sim 2-3 \mathrm{emA}$. The need to supply beams to multiple users "simultaneously" determines the requirement for species switching in 1 second.

Table 1: Performance Requirements of the Preinjector

\begin{tabular}{|l|l|}
\hline Species & He to $\mathrm{U}$ \\
\hline Intensity (examples) & $2.7 \times 10^{9} \mathrm{Au}^{32+} /$ pulse \\
& $\begin{array}{l}4 \times 10^{9} \mathrm{Fe}^{20+} / \text { pulse } \\
5 \times 10^{10} \mathrm{He}^{2+} / \text { pulse }\end{array}$ \\
\hline $\mathrm{Q} / \mathrm{m}$ & $\geq 0.16$, depending on ion species \\
\hline Repetition rate & $5 \mathrm{~Hz}$ \\
\hline Pulse width & $10-40 \mu \mathrm{s}$ \\
\hline $\begin{array}{l}\text { Switching time } \\
\text { between species }\end{array}$ & 1 second \\
\hline Output energy & $2 \mathrm{MeV} / \mathrm{amu}$ \\
\hline
\end{tabular}

\footnotetext{
* Work supported by the US Department of Energy and the National Aeronautics and Space Administration.

\# alessi@bnl.gov
}

An EBIS is ideally suited for meeting the requirements of producing short pulses of highly charged heavy ions at high currents, along with fast switching of species without any deleterious "memory" effects. An ion source, which meets these requirements is now under construction at BNL. The RFQ and Linac to accelerate the beams to the final energy of $2 \mathrm{MeV} / \mathrm{amu}$ are under construction at IAP, Frankfurt [2].

The primary means of seeding the trap of the RHIC EBIS will be injection and trapping of single (or low) charged ions from an external ion source. This technique has been used very successfully, and allows one to produce a very narrow charge state distribution. With ion injection, the EBIS functions purely as a charge state multiplier, and the processes involved in low charge state ion production can be done in various easily accessible external ion sources. Only the necessary numbers of seed ions are injected into the ultrahigh vacuum EBIS ionization volume. The requirements of the external source are relatively modest, needing to produce currents of 10-100 $\mu \mathrm{A}$ of singly charged ions. Advantages of an EBIS working with ion injection are that the ion species and charge state can be easily changed on a pulse to pulse basis, there is no contamination or memory effect, and several relatively low cost external sources can be connected maintained independently of the EBIS. For switching quickly (pulse-to-pulse) between two species, two external injection sources will be used.

The LEBT line, therefore, must allow injection of these singly charged ions, and then the settings for the shared elements must switch within a few milliseconds to transport and match the EBIS extracted ion beam into the RFQ. The functions of this LEBT line are shown schematically in Figure 1.

\section{LEBT DESIGN}

High beam transmission and minimal emittance growth under high space charge are requirements of the LEBT. In addition, one must allow space for injection of the singly charged ions into the EBIS trap, and for beam instrumentation required for fast beam setups. A prototype of this beamline, as shown in Fig. 2, is being built as part of the R\&D program. An extraction energy of $17 \mathrm{keV} / \mathrm{amu}$ was chosen, high enough to minimize space charge effects in the LEBT line, without being excessive, such that voltage holding becomes more difficult, and the RFQ length increases. 


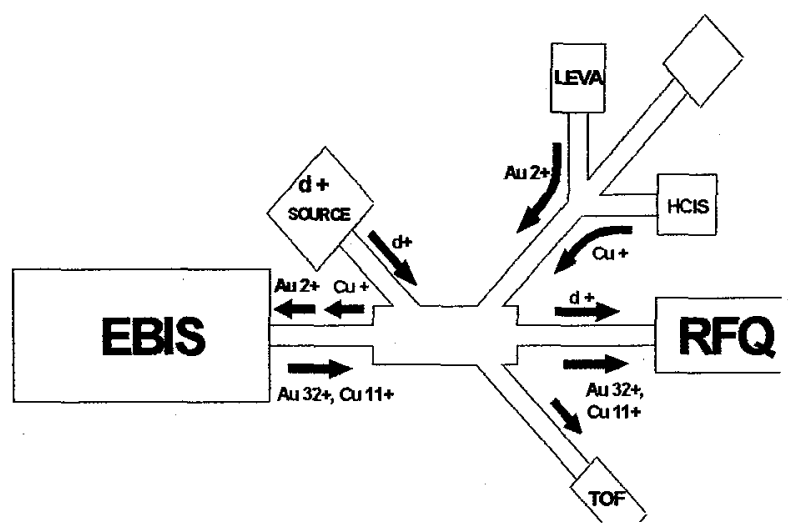

Figure 1 Functions of the LEBT line. TOF: Time-offlight; LEVA:Low Energy Vacuum Arc source; HCIS: Hollow Cathode Ion Source.

After exiting the EBIS accelerating column, the first focusing element is a gridded electrostatic lens. While the use of a grid results in a $\sim 10 \%$ loss in current, it was chosen because it can provide focusing or defocusing as required by the particular beam species. This can be switched within $\sim 1 \mathrm{~ms}$, to allow different focusing for the incoming, singly charged ions, and the extracted, highly charged ions. A pulsed magnetic solenoid lens focuses the beam into the RFQ. The distance between the two lenses is kept as short as possible, in order to minimize space charge blowup of the high perveance extracted ion beam. The LEBT includes pulsed electrostatic deflectors for injection of singly charged ions into the EBIS trap, deflection of highly charged ions into a diagnostic line (time-of-flight spectrometer), and a deflector which allows ions to be injected directly in to the RFQ from an auxiliary source on a spur line, if desired. Figure 3 shows a calculation of the beam optics for $\mathrm{Au}^{32+}$ through the electron collector, $100 \mathrm{kV}$ accelerating column, and then the matching lenses into the RFQ. The open aperture through the entire line between the EBIS and RFQ is 10 $\mathrm{cm}$ diameter.

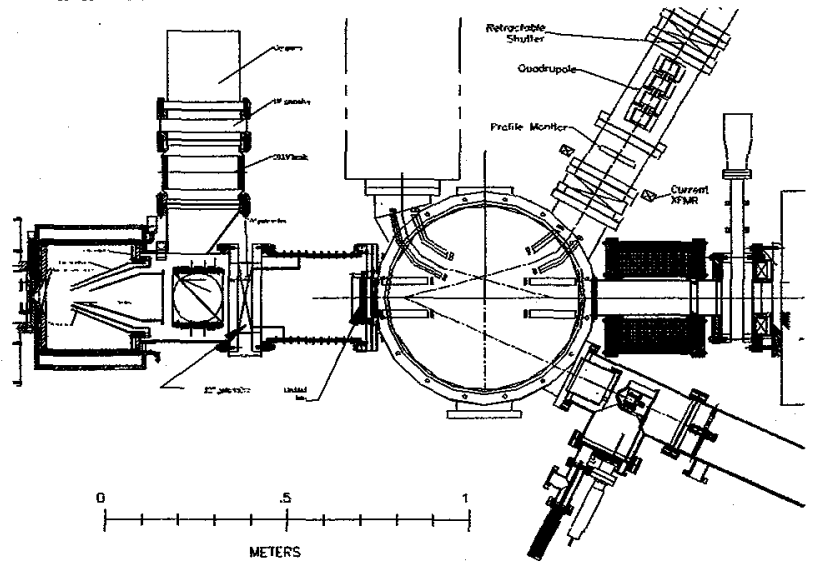

Figure 2: LEBT, matching between the EBIS (left) and the RFQ entrance (right). Externally injected 1+ ions come from the spur line on the upper right, and a time-offlight spectrometer is located in the spur line on the lower right in the figure.

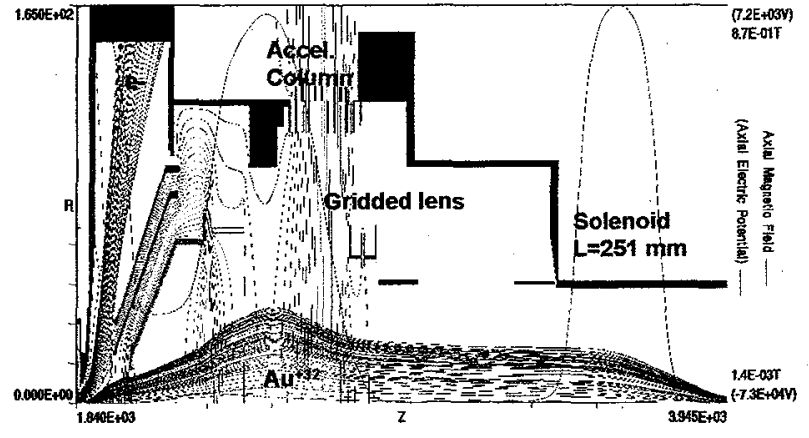

Figure 3: TRAK simulation for an $8 \mathrm{~mA} \mathrm{Au}^{32+}$ beam. The distance from the electron collector entrance (left) to the RFQ entrance (right) is $2.1 \mathrm{~m}$.

\section{EXTERNAL ION INJECTION LINES}

The beamlines for matching multiple external ion sources to the LEBT use only electrostatic focusing and deflection, for easier fast switching of ion species. All beamlines have essentially the same optical components. A Wien filter at the exit of the source, for mass separation, is followed by electrostatic steerers, an electrostatic quadrupole triplet, then a spherical deflector to bend the beam into a shared transport line. After this bend, there is $H \& V$ electrostatic steering, and four electrostatic quadrupoles to match into the second spherical deflector. Both spherical deflectors are 44 degree bends, with $5 \mathrm{~cm}$ plate separation.

\section{DIAGNOSTICS}

There are a variety of diagnostics in the LEBT line, to allow efficient setup of the externally injected ions, tuning of the EBIS for the desired charge state, and extraction and matching into the RFQ. The externally injected ion current can be measured on Faraday cups in each source beam line, on a current transformer (CT) just upstream of the LEBT chamber, and on a CT between the LEBT chamber and the EBIS. There is also a multiwire profile monitor to measure the externally injected ions before they enter the LEBT line.

The charge state distribution of the extracted EBIS beam can be measured with a Mamyrin time-of-flight spectrometer by deflecting the extracted ions off axis into a spur line in the lower right of Figure 2. Extracted current is measured on CT's at the entrance to the LEBT chamber and at the entrance to the RFQ. In the center of the LEBT chamber, there will be a retractable multiwire profile monitor and emittance measuring unit.

\section{PROTOTYPE LEBT}

A prototype LEBT chamber has been built, to test the performance of the matching of the external ions into EBIS, and to transport and measure the emittance of the EBIS beam at the RFQ entrance location. When the RFQ is delivered, initial beam test will be done on the Test EBIS using this LEBT beamline. 
Initial tests of the injection of externally produced $1+$ ions on to the axis of the EBIS are in progress. Beam from a hollow cathode ion source (HCIS) [3] is matched into the LEBT deflectors using four independently controlled electrostatic quadrupoles, each with $5 \mathrm{~cm}$ long poles and $5 \mathrm{~cm}$ diameter aperture. The injected beam then passes through the $\mathbf{4 4}$ degree spherical deflector, and is finally deflected 16 degrees onto the EBIS axis using a parallel plate deflector. For these initial tests, the emittance can be measured at the exit of the LEBT using both a slit-collector and pepperpot emittance devices. An example of the emittance of a $10 \mathrm{uA}, 11 \mathrm{kV} \mathrm{Cu} 1+$ beam at the output of the LEBT is shown in Figure 4. The aberrations measured are consistent with $3 \mathrm{D}$ calculation using KOBRA, when the beam fills a large fraction of the aperture in the quadrupoles and deflectors. Figure 5 shows the output emittance when the beam entering the quadrupoles is collimated to $1.8 \mathrm{~cm}$ diameter. There is a plan to improve the optics of the beam at the output of the HCIS, so that this collimation can be avoided. We are able to obtain emittances which are symmetric in $x$ and $y$, as desired. To date, transmission through the LEBT $>90 \%$ has been achieved without collimation $(15 \mu \mathrm{A}$ $\mathrm{Cu}+$ ), and with collimation upstream of the quadrupoles, up to $100 \%$ has been obtained $\left(9 \mu \mathrm{A} \mathrm{Cu}^{+}\right)$. This performance is more than adequate to obtain the required intensity of injected $1+$ ions. Output emittances with collimation are $\leq 0.02 \mathrm{pi} \mathrm{mm} \mathrm{mrad}$, normalized, rms. While we are continuing to characterize this LEBT, these initial measurements on the performance for ion injection are quite encouraging.
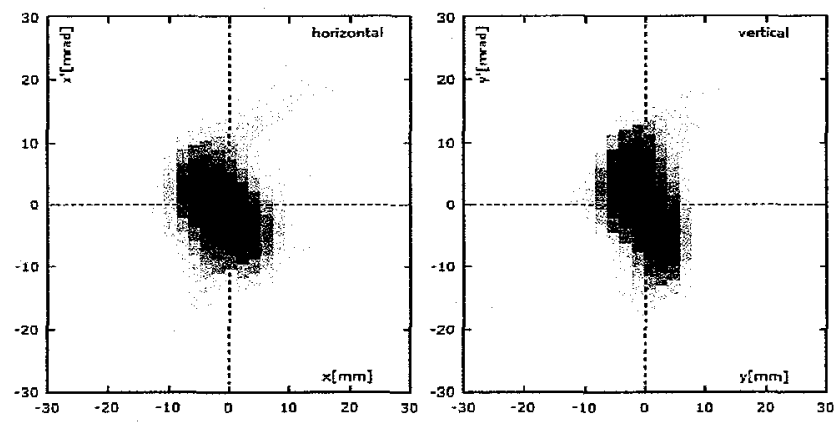

Figure 4: Emittance at the exit of the LEBT chamber, $\mathrm{Cu}^{1+}, 11 \mathrm{keV}, 10 \mu \mathrm{A}$.
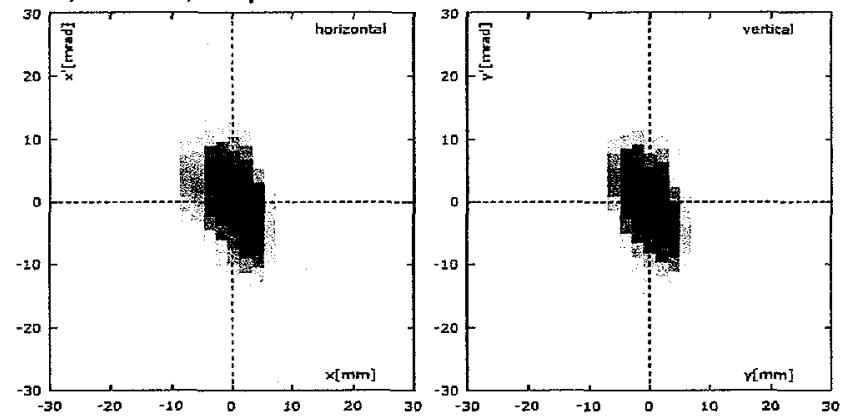

Figure 5: Emittance at the exit of the LEBT chamber when the beam is collimated between the ion source and the first quadrupole.

\section{LEBT pulsed solenoid}

The laminated steel core solenoid has a length of 251 $\mathrm{mm}$, and a bore diameter of $12 \mathrm{~cm}$. A pulsed current of $\sim 1800 \mathrm{~A}$ is required in order to provide the required field of $\sim 8.7 \mathrm{kG}$. This pulsed solenoid is very similar to units used to match $\mathrm{H}$ - beam into the proton $\mathrm{RFQ}$ on the $\mathrm{BNL}$, $200 \mathrm{MeV}$ linac. A prototype solenoid has been fabricated, and is shown in Figure 6. This solenoid will be mounted on the LEBT chamber for testing of the transport of the extracted EBIS beam to the RFQ entrance point.

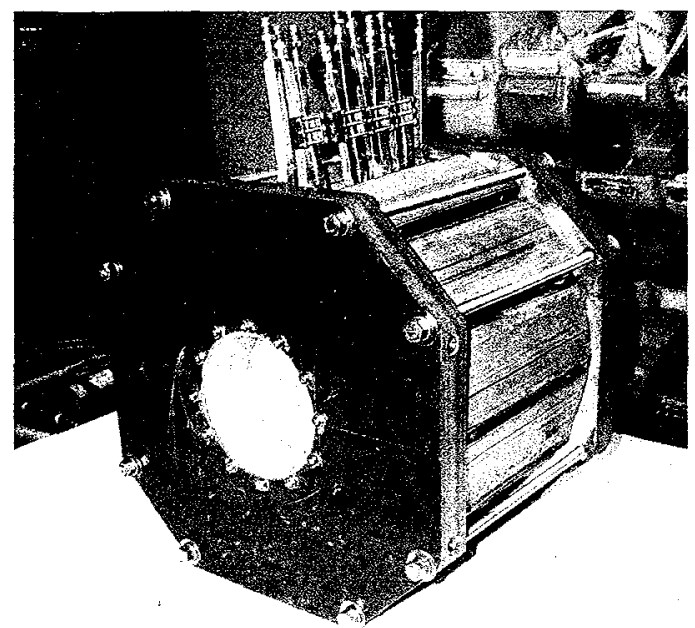

Figure 6: Pulsed LEBT solenoid.

\section{CONCLUSION}

The detailed design is complete for extraction and matching of the high current EBIS output beam into the RFQ, and for the beamlines for injecting low current $1^{+}$ ions from external ion sources into the EBIS trap. Prototypes of the LEBT chamber with electrostatic deflectors, the electrostatic quadrupoles, and the LEBT solenoid have been fabricated and are being tested. All diagnostics are either existing, or based on existing units.

\section{ACKNOWLEDGEMENTS}

We would like to thank D. McCafferty, R Schoepfer, and $\mathrm{W}$. Shaffer for their excellent technical support on this project.

\section{REFERENCES}

[1] J. Alessi, et.al., "High-Performance EBIS for RHIC", these proceedings.

[2] A. Schempp, et.al., "RFQ and IH accelerators for the new EBIS injector at BNL", these proceedings.

[3] B. Visentin, et.al., Physica Scripta T71 (1997) 204206. 